\title{
Asset Thresholds and Social Protection: A Reply to Dercon
}

\author{
Michael R. Carter and Christopher B. Barrett
}

We thank Stefan Dercon for his typically insightful comments on our think-piece on asset thresholds and social protection. It is reassuring and unsurprising that we agree on most key points: (1) asset thresholds and poverty traps are a reality in at least some contexts, (2) the resulting policy implications should not be understated as social protection, done right, then offers extremely high returns, (3) risk acquires particular salience in this setting and thus risk management and social protection merit more careful attention by both researchers and development practitioners, and (4) there is a crucial practical and conceptual difference between protecting the vulnerable from a collapse into destitution and helping the poorest to transform their long-term prospects. Indeed, there is often a difficult trade-off between these two worthy activities, one we should not shy away from by falsely suggesting - as so much of the current literature does - that the two objectives are perfectly coincident. The development community needs to engage in more substantive discussion about whether and how to perform triage in interventions.

We also wholeheartedly agree with several points Stefan emphasises more than our think-piece did, notably: (a) the multidimensionality of productive assets and the challenge this poses to empirical identification of necessarily multidimensional thresholds, (b) the existence of critical exclusionary mechanisms unrelated to finance - such as ethnic, gender, racial or religious discrimination - and (c) the important ex ante effects of risk exposure in discouraging productive investment by poor households (a point addressed specifically in Carter and Barrett (2006) and Barrett et al. (2007)). We especially agree that phenomena at more aggregate levels than the individual household play a fundamental role in shaping the incentives and exclusionary mechanisms commonly associated with poverty traps, as some of our recent joint and separate work has emphasised (Barrett 2005; Barrett and Swallow 2006; Carter and Castillo 2006).

We likewise share Stefan's caution about the limited evidence base and methodological challenges of estimating asset thresholds, and about the need to start thinking about the general equilibrium effects of large-scale transfers to the very poor and of threshold-based social protection for the vulnerable. We perhaps do not wring our hands as much about these matters, not because we find the evidence on asset thresholds rock solid and the policy implications obvious and clearly documented, but because the alternatives strike us as having no firmer empirical or theoretical basis. It is absolutely true that 'the evidence available [on poverty traps] from most settings is at best controversial, and at worst, largely non-existent'.

But this equally describes claims against the poverty traps hypothesis. The chief difference is that tests that fail to reject the 'no poverty trap' null hypothesis have low statistical power because they presume with little or no solid empirical support - the veracity of models that assume away thresholds and exclusionary mechanisms. Yet those models have largely failed to deliver for a billion or more people whose problems have defied the traditional prescriptions based on simpler models (Collier 2007).

As George Box famously asserted, 'all models are wrong, some are useful'. We submit that the poverty trap model based on asset thresholds - while surely oversimplified in some aspects and more challenging to implement empirically than its simpler 
counterpart - is useful for a variety of purposes, not least being for usefully pushing our collective thinking about social protection. Indeed, one can argue that it is precisely because poverty traps are hard to pin down, that most researchers and policymakers have relied on oversimplified models that have repeatedly failed. One needs to be very careful about discouraging explorations beyond the realm of the familiar but failed!

So where do we disagree with the comments put forward by Stefan? At the end of his comments, Stefan suggests that sufficiently rapid economic growth that eliminates the small-scale agricultural and informal activities that require assets and finance may obviate the need to worry about traps and thresholds. While one can dispute the empirical veracity of this claim (witness the growing discussion on asset traps and thresholds in the well-developed economies of the USA and the UK), ${ }^{1}$ we need also to be wary of the passivity of what is essentially a postmodern reformulation of 'trickle-down'. Global GDP has grown by an average annual rate of nearly 4 per cent over the past decade; nonetheless the number of people living on US\$2/day or less has remained unchanged and real wages for unskilled workers are stagnant or falling in most nations. This is true even in rapidly growing countries, such as India, in which a large share of the population appears trapped and

\section{Note}

1 See, for example, the theoretical work of Buera (2005) and the array of asset-building interventions piloted by Michael Sherraden and

\section{References}

Barrett, C.B., ed. (2005) The Social Economics of Poverty: On Identities, Groups, Communities and Networks, London: Routledge

Barrett, C.B. and Swallow, B.M. (2006) 'Fractal Poverty Traps', World Development 34.1: 1-15

Buera, F. (2005) A Dynamic Model of Entrepreneurship with Borrowing Constraints, Working Paper, Evanston: Northwestern University

Carter, M.R. and Castillo, M. (2006) Trustworthiness and Social Capital in South Africa: An Experimental left behind even as tens of millions of their fellow citizens make rapid progress.

Lowering or eliminating the asset thresholds and exclusionary mechanisms that jointly trap hundreds of millions of people in persistent poverty is indeed a crucial, complementary strategy to social protection. In the longer run it may offer the highest returns, in terms of less chronic or acute poverty. But we know even less about how to obviate thresholds and exclusion than we do about identification of thresholds. For example, heroic efforts to dismantle the exclusionary mechanisms of the apartheid state have not brought relief to most desperately poor people in South Africa (Carter and May 2001). Similarly, extensive efforts to develop intermediate technologies to help small farmers transition from rudimentary to modern production methods have largely failed, at least in Africa.

In the end, as Stefan's comments make clear, there is a lot we do not know about identifying thresholds and resolving exclusion. However, thanks to the efforts of Stefan and others to illuminate the importance of exclusion based on caste, gender, race and religion, we can be sure that we need to look beyond a simple trust in 'labour-intensive economic growth' to untangle the knot of persistent poverty.

the Centre for Social Development at Washington University in Saint Lovis (available at http://gwbweb.wustl.edu/csd/asset/index.htm).

Approach, Working Paper, Madison: University of Wisconsin

Carter, M.R. and May, J. (2001) 'One Kind of Freedom: The Dynamics of Poverty in PostApartheid South Africa', World Development 29: 1987-2006

Collier, P. (2007) The Bottom Billion: Why the Poorest Countries are Failing and What Can be Done About It, Oxford: Oxford University Press 